\title{
Estudo comparativo de dois métodos para obtenção de células mesenquimais indiferenciadas de tecido adiposo*
}

\section{Comparative study of two different methods of harvesting adipose tissue derived stem cell}

\author{
Francinni Mambrini Pires Rêgo', Aline de Paula da Cruz', \\ Cristina Nicoli de Mattos ${ }^{1}$, Rafael Mamoru Carneiro Tutihashi², \\ César Isaac ${ }^{3}$, Marcus Castro Ferreira ${ }^{4}$
}

Rego FMP, Cruz A de P da, Mattos CN de M, Tutihashi RMC, Isaac C, Ferreira MC. Estudo comparativo de dois métodos para obtenção de células mesenquimais indiferenciadas de tecido adiposo. Rev Med (São Paulo). 2009 jan.-mar.;88(1):16-9.

\begin{abstract}
RESUMO: Introdução: Perdas de tecido mesenquimal podem acarretar grandes áreas cruentas, cujos tratamentos nem sempre são isentos de morbidade. A participação de células mesenquimais indiferenciadas, no processo de cura de feridas, tem sido amplamente estudada. Objetivo: comparar dois métodos de obtenção de células mesenquimais indiferenciadas de tecido adiposo. Métodos: amostras padronizadas de fragmentos de tecidos gordurosos provenientes de lipectomia (L) e de lipoaspiração (LA) foram mantidas em cultura celular em placas multipoços de 6 poços por 72 horas e posteriormente descartadas. Após 96 horas do descarte, as células aderidas às superfícies de cultura foram soltas e contadas em câmara hemocitométrica. Resultados: no grupo LA a média do número de células encontradas foi $9,4 \times 10^{4}$, enquanto que no grupo L o número de células encontrado foi 0 (zero). Conclusão: na comparação dos métodos, foram obtidas células somente a partir de produto de lipoaspiração.
\end{abstract}

DESCRITORES: Lipectomia. Técnicas de cultura de células. Células-tronco mesenquimais. Tecido adiposo/cirurgia.

\footnotetext{
* Trabalho premiado no COMU - 2008. Área Básica - Prêmio Oswaldo Cruz, 2008.

1. Acadêmica da Faculdade de Medicina da Universidade de São Paulo.

2. Médico do Departamento de Cirurgia Plástica do Hospital das Clínicas da Faculdade de Medicina da Universidade de São Paulo.

3. Médico Doutor pela Faculdade de Medicina da Universidade de São Paulo.

4. Professor Titular do Departamento de Cirurgia Plástica da Faculdade de Medicina da Universidade de São Paulo. Endereço para Correspondência: Francinni Mambrini Pires Rego. Av. Dr. Arnaldo, 455, sala 1360. São Paulo, SP. CEP: 01246-903. E-mail: cinninha@uol.com.br
} 


\section{INTRODUÇÃO}

A perda de tecidos de origem mesenquimal, tais como lesões traumáticas ou ressecções tumorais podem gerar grandes áreas cruentas. Atualmente, a solução para a reconstrução desses defeitos é a utilização de auto-enxertos, retalhos ou próteses, porém, nem sempre apresentam resultados estéticos satisfatórios, além de serem acompanhadas de morbidade no sítio doador no caso de enxertos e retalhos ou de implantes de materiais sintéticos. Frente a este cenário, a engenharia de tecidos poderá nos trazer uma alternativa para reconstrução dessas feridas.

A participação de células mesenquimais indiferenciadas no processo de cura da ferida tem sido amplamente estudada. Estas células foram inicialmente obtidas por punção de medula óssea. No entanto, já foi comprovado que no tecido adiposo existe também grande número dessas células, semelhantes às obtidas da medula óssea, com idêntico potencial de diferenciação ${ }^{3}$, e apresentando vantagens como a facilidade de obtenção por causar menos desconforto ao paciente e por ter uma fonte abundante. A obtenção pode ser feita tanto a partir de fragmento de lipectomia, quanto de produto de lipoaspiração. $\mathrm{Na}$ literatura está consagrado que na obtenção a partir do produto de lipoaspiração há maior número de células e maior potencial de diferenciação nas diversas linhagens ${ }^{1}$.

\section{OBJETIVO}

Comparar a obtenção de células mesenquimais indiferenciadas a partir de fragmentos de lipectomia e produto de lipoaspiração.

\section{MATERIAL E MÉTODO}

Foram obtidos fragmentos de lipectomia de três pacientes e produto de lipoaspiração de três pacientes distintos. Não houve seleção por gênero, a idade variou entre 34 e 62 anos. O material foi transportado ao laboratório de cultura celular em Meio de Eagle Modificado por Dulbecco (DMEM) acrescido de $10 \%$ de Soro Bovino Fetal e $1 \%$ de solução antibiótica e antimicótica (composto por penicilina $\mathrm{G} 10.000 \mu \mathrm{g} / \mathrm{mL}$, estreptomicina $25 \mu \mathrm{g} /$ $\mathrm{mL}$, anfotericina $\mathrm{B} 0,85 \%$ ), que por nós foi intitulado "D10". Os produtos foram separados em dois grupos: lipectomia (L) e lipoaspiração (LA).

$O$ material do grupo $L$ foi processado imediatamente após a chegada no laboratório da seguinte maneira: irrigação com solução estéril de cloreto de sódio $0,9 \%$ por 10 minutos, o procedimento foi repetido 2 vezes. Foram separados 6 fragmentos de aproximadamente $5 \mathrm{~mL}$ cada e colocados individualmente em um poço de uma placa multipoço de 6 poços. Todos os fragmentos foram imersos em $3 \mathrm{~mL}$ de D10. As placas foram incubadas à $37^{\circ} \mathrm{C} \mathrm{com}$ atmosfera de $5 \% \mathrm{CO}_{2}$, os fragmentos foram retirados no $3^{\circ}$ dia e o meio de cultura foi trocado a cada 3 dias.

O material do grupo LA foi processado imediatamente após a chegada no laboratório da seguinte maneira: irrigação com solução estéril de cloreto de sódio $0,9 \%$ por 10 minutos, o procedimento foi repetido 2 vezes. Foram separados $30 \mathrm{~mL}$, divididos igualmente em seis poços de uma placa multipoço de 6 poços, contendo, aproximadamente, $5 \mathrm{~mL}$ do produto de lipoaspiração e $3 \mathrm{~mL}$ de D10. A placa foi mantida à $37^{\circ} \mathrm{C}$, o sobrenadante, composto por produto de LA, foi retirado no $3^{\circ}$ dia e o meio de cultura foi trocado a cada 3 dias.

Após 1 semana, em ambos os grupos, as células foram contadas em câmara hemocitométrica, sendo consideradas apenas as células com formato arredondado contendo núcleo.

\section{RESULTADOS}

O número de células do grupo LA foi $9,4 \times 10^{4}$ células (Tabela 1).

Tabela 1. Comparação entre grupos lipectomia (L) e lipoaspiração (LA) - média do número de células $\times 10^{4}$

\begin{tabular}{c|c|c}
\hline Grupo & Lipectomia & Lipoaspiração \\
\hline Células $\left(\times 10^{4}\right)$ & 0 & 9,4 \\
\hline
\end{tabular}

Ao $3^{\circ}$ dia de cultura, o grupo LA apresentava células mesenquimais entremeadas à adipócitos (Figura 1).

Após 7 dias já havia confluência de células mesenquimais e menor número de adipócitos (Figura 2).

Não foram obtidas células do grupo L. 
Rego FMP et al. Estudo comparativo de dois métodos para obtenção de células mesenquimais.

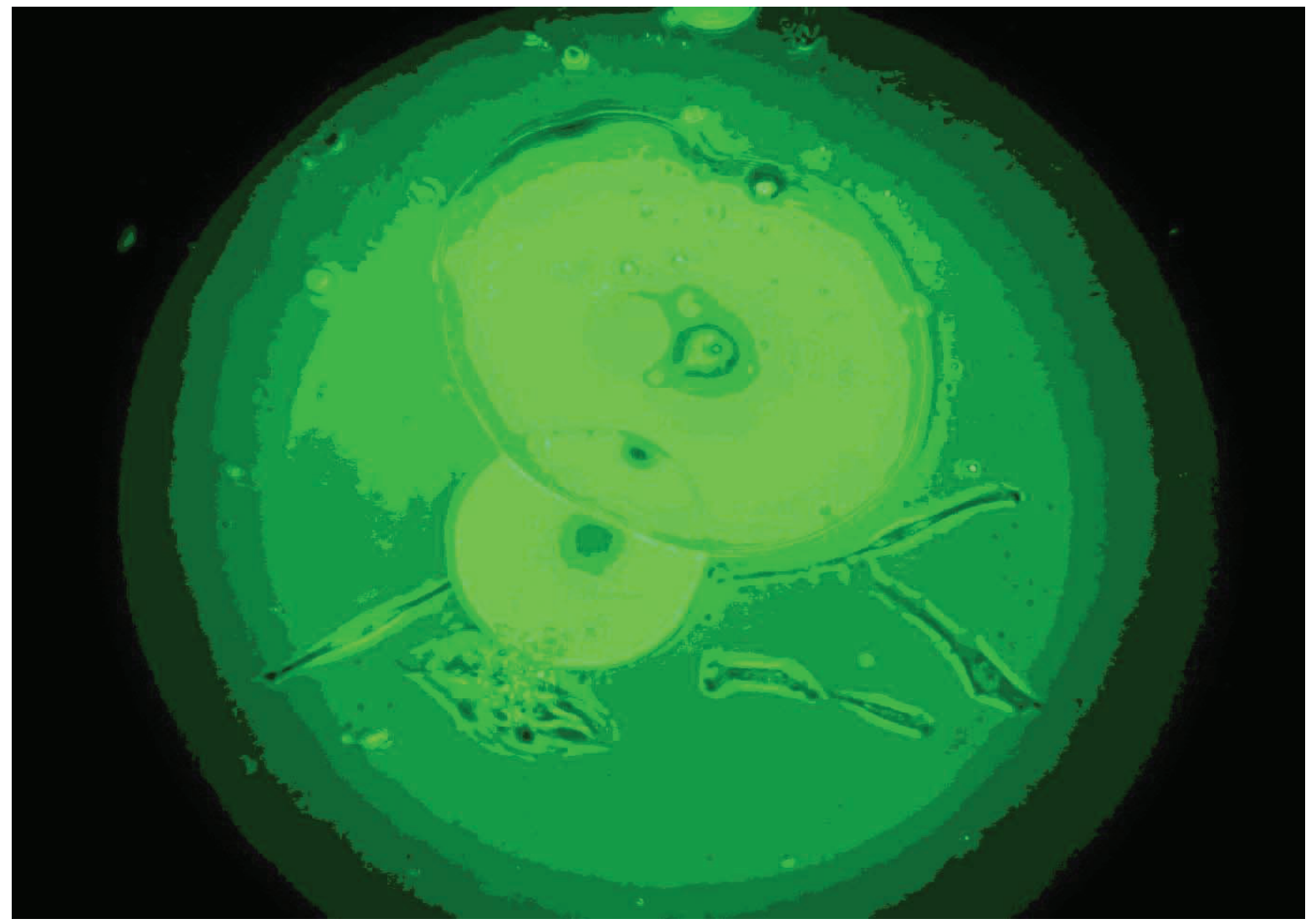

Figura 1. Células mesenquimais indiferenciadas (A); entremeadas com adipócitos (B). 3ํ dia de cultura celular. MOC 100X

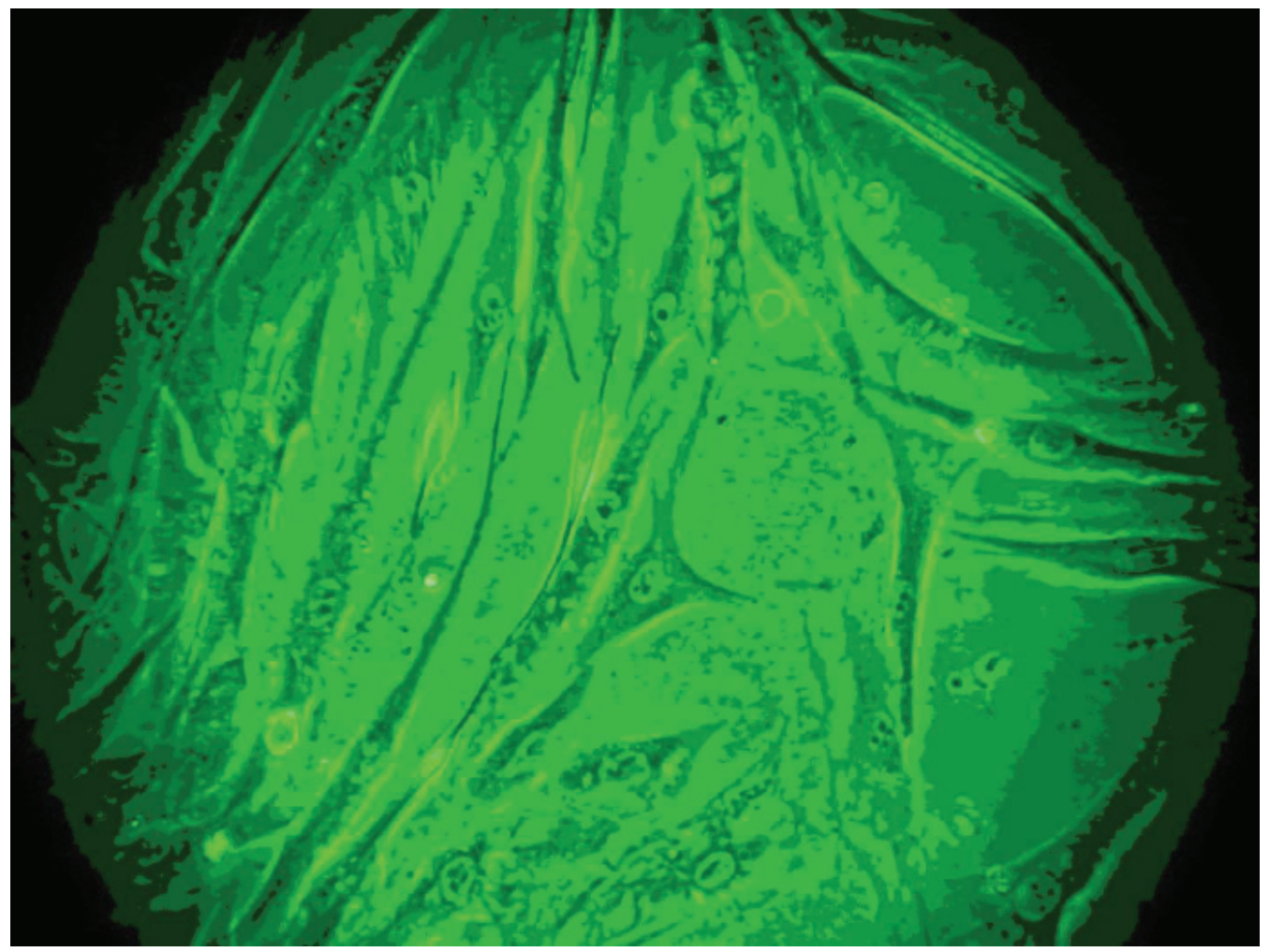

Figura 2. Células mesenquimais indiferenciadas confluentes no $7^{\circ}$ dia de cultura. MOC $100 \mathrm{X}$ 


\section{DISCUSSÃO}

De acordo com a literatura é possível obter células mesenquimais indiferenciadas a partir de fragmentos de lipectomia. Em nosso trabalho não obtivemos células neste grupo. Acreditamos que este fato se deva ao pouco tempo de permanência do fragmento em meio de cultura (apenas 3 dias), porém este período de contato mostrou-se suficiente para obtenção de células no grupo LA. Revendo publicações existentes sobre obtenção de células mesenquimais indiferenciadas a partir de tecido adiposo, o procedimento de lipoaspiração mostra-se mais eficaz, o que corrobora com nossos achados.

A maioria dos protocolos de obtenção de células mesenquimais indiferenciadas envolve digestão enzimática tanto do produto de lipoaspiração quanto do fragmento de lipectomia. No entanto esses protocolos são mais trabalhosos e demorados, em média duram 2 a 3 horas. ${ }^{1,2} \mathrm{O}$ objetivo da padronização metodológica proposto neste estudo foi oferecer uma forma de obtenção de células mesenquimais indiferenciadas mais simples. Entretanto ainda são necessários outros estudos comparando o método com digestão enzimática de produtos de lipoaspiração com o nosso protocolo de decantação de produto de lipoaspiração para determinarmos qual será o método de eleição para obtenção de células mesenquimais indiferenciadas em nosso serviço.

\section{CONCLUSÃO}

Na comparação dos métodos observamos que foram obtidas células somente a partir do produto de lipoaspiração.

Rego FMP, Cruz A de P da, Mattos CN de M, Tutihashi RMC, Isaac C, Ferreira MC. Comparative study of two different methods of harvesting adipose tissue derived stem cell. Rev Med (São Paulo). 2009 jan.-mar.;88(1):16-9.

\begin{abstract}
Introduction: Mesenchymal tissue loose can lead to large wounds, which treatments are not completely free of morbidity. The adipose tissue derived stem cell participation in wound healing process has been widely studied. Objective: The aim of the study is to compare two different methods of harvesting adipose tissue derived stem cell. Methods: Standard amounts of adipose tissue from lipectomy (L) and liposuction (LA) have been kept in cell culture for 72 hours in 6 well clusters and then discharged. 96 hours after the discharge cells were tripsynized from the multi-well culture surface and counted on hemocitometer chamber. Results: The mean number of cells from LA group was $9.4 \times 10^{4}$, in the $L$ group the number of cell was 0 (zero). Conclusion: Comparing the 2 methods, cells were harvested only from the liposuction group.
\end{abstract}

KEY WORDS: Adipose tissue derived stem cell/surgery. Lipectomy. Cell culture techniques mesenchymal. Stem cells.

\title{
REFERÊNCIAS
}

1. Mizuno $\mathrm{H}$, Hyakusoku H. Mesengenic potential and future clinical perspective of human processed lipoaspirate cells. J Nippon Med Sch. 2005;70(4): 300-6.

2. Miyazaki T, Kitagawa Y, Toriyama K, Kobori M, Torii S. Isolation of two human fibroblastic cell populations with multiple but distinct potential of mesenchymal differentiation by ceiling culture of mature fat cells from subcutaneous adipose tissue. Differentiation. 2005; 73:69-78.

3. Vermette M, Trottier V, Ménard V, Saint-Pierre L, Roy A, Fradette J. Production of a new tissue-engineered adipose substitute from human adipose-derived stromal cells. Biomaterials. 2007;28:2850-60. 